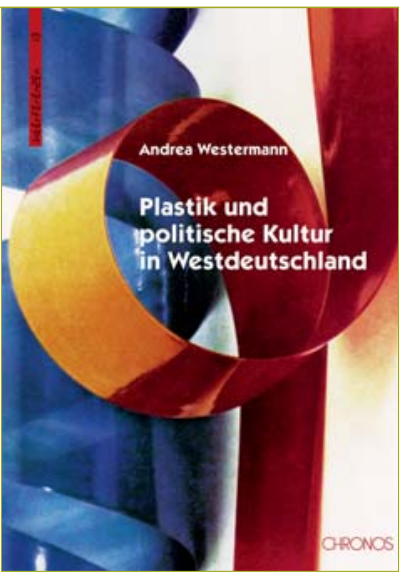

Westermann, A. 2007. Plastik und politische Kultur in Westdeutschland. Reihe Interferenzen - Studien zur Kulturgeschichte der Technik, Band 13. Zürich: Chronos. 392 S., 38,- EUR, 58,- CHF, ISBN 978-3-0340-0849-5

\section{Die Politisierung des Konsums}

\author{
Polyvinylchlorid (PVC) läutete in den 1950er Jahren \\ die massenhafte Ankunft von Plastik in Westdeutschland ein - \\ und gilt als Sinnbild dafür, dass sich die \\ Nachkriegsgesellschaft in hohem Maß auf \\ technische Innovation verließ, um soziale Ordnung \\ zu etablieren. Ab den 1960er Jahren wurde diese Ordnung \\ erschüttert: PVC geriet wiederholt als gesundheits- \\ und umweltschädlich in die Kritik. \\ vorgelegt. PVC war in den 1930er Jahren \\ von der IG Farbenindustrie AG entwickelt \\ worden und läutete ab den 1950er Jahren \\ die massenhafte Verbreitung von Kunst- \\ stoffen in der BRD ein. Seit Mitte der 60er \\ Jahre stand PVC im Zentrum erster Ge- \\ sundheits- und Umweltdiskurse. \\ Westermanns Studie geht von der The- \\ Polyvinylchlorid \\ wurde zum Gegenstand \\ öffentlichen Engagements \\ und Kristallisationskeim \\ politischer Protest- \\ bewegungen.
}

ass der Umgang mit Dingen und Stoffen auch eine zentrale kulturelle und politische, nicht nur eine technische und ökonomische Dimension hat, ist uns im Alltag geläufig. Und das Gewicht der Dinge scheint in den letzten Jahren noch zugenommen zu haben. Nicht mehr nur über unsere gesellschaftliche Position und unsere Einstellung können wir durch Erwerb und Konsum symbolisch Auskunft geben, nein, zunehmend wird uns auch - mit Bioprodukten, „ $\mathrm{CO}_{2}$-neutralen“ Waren und Dienstleistungen oder „fair“ gehandelten tropischen Produkten - die Möglichkeit eröffnet oder vorgegaukelt, eine bessere Welt gewissermaßen herbeikonsumieren zu können. Dieses Phänomen wurde als „Moralisierung der Märkte“ " , aber auch als „Universalisierung des Fetischismus in der Moderne“2 beschrieben.

\section{PVC in der BRD}

Zum Verständnis unseres Umgangs mit Dingen und Stoffen vermögen aber vielleicht mehr als solche Schlagworte historische Fallstudien beizutragen. Die Technikhistorikerin Andrea Westermann hat mit ihrer Untersuchung zur Geschichte von Polyvinylchlorid (PVC) in Westdeutschland von 1900 bis 1980 eine Studie über den ersten vollsynthetischen Kunststoff

1 Stehr, N. 2007. Die Moralisierung der Märkte. Eine Gesellschaftstheorie. Frankfurt am Main: Suhrkamp.

2 Böhme, H. 2006. Fetischismus und Kultur. Eine andere Theorie der Moderne. Reinbek: Rowohlt. se aus, dass der Konsum in der Bundesrepublik von Anfang an einen politischen Inhalt hatte, ja, sie bezeichnet die frühe Bundesrepublik, im Anschluss an andere Autoren, als „Verbraucherdemokratie“. Die Zustimmung zu dem jungen, demokratischen Staatswesen, das unter der Aufsicht der Siegermächte entstand, habe sich erst durch den Konsum eingestellt und über diesen schließlich gefestigt. PVC als Stoff, der den Konsum auch solcher Artikel ermöglichte, die zuvor nur wenigen vorbehalten waren, wurde zu einem zentralen, zunächst positiv besetzten Symbol jener „Verbraucherdemokratie“. PVC-Produkte zu nutzen bedeutete auch, mitzumachen beim Wirtschaftswunder und Teil eines neuen, modernen Staates zu sein, der seine schreckliche Vergangenheit so schnell wie möglich hinter sich lassen wollte.

\section{Ein Schlag gegen die Verbraucher- demokratie}

Gerade weil die Zustimmung zu PVC zunächst allgemein und ungebrochen war, konnte der Stoff auch eine tiefgreifende Krise jener „Verbraucherdemokratie“ auslösen. Das Monomer des PVC, das Vinylchlorid, erwies sich als gesundheitsschäd- lich, später sogar als krebserregend, was zunächst die Arbeiter(innen) der Kunststoffindustrie, dann aber auch potenziell alle Nutzer(innen) von PVC-Produkten betraf. Dies erschütterte das Vertrauen in die „Verbraucherdemokratie“ nachhaltig. Der Stoff wurde zum Gegenstand vielfältigen öffentlichen Engagements und einer der Kristallisationskeime politischer Protestbewegungen.

Neben der souverän durchgeführten, bis in Details sorgfältigen Argumentation besticht die Studie durch eine gepflegte, an vielen Stellen pointierte Sprache. Andrea Westermann zeigt schlüssig, dass die Politisierung des Konsums kein neues Phänomen ist, auch wenn sie in früheren Zeiten nicht so explizit war wie heute. Auch deshalb ist ihr Buch ein Beitrag zu einem tieferen Verständnis unseres Umgangs mit Dingen und Stoffen.

Kontakt: Dr. Jens Soentgen | Wissenschaftszentrum Umwelt | Universität Augsburg | Augsburg | Deutschland | E-Mail: soentgen@wzu.uni-augsburg.de 